\title{
Legislação sobre posse de terras e Educação do Campo no Brasil
}

\author{
Elizabeth Moreira Gomes ${ }^{1}$, Alexandre Fraga de Araújo $^{2}$, Maria Isabel Antunes-Rocha ${ }^{3}$ \\ ${ }^{1}$ Instituto Federal do Norte de Minas Gerais - IFNMG. Campus Araçuaí. Fazenda do Meio Pé da Serra, s/n, BR 367, km 278. \\ Araçuaí-MG. Brasil. ${ }^{2}$ Instituto Federal do Espírito Santo - IFES. ${ }^{3}$ Universidade Federal de Minas Gerais - UFMG. \\ Autor para correspondência/Author for correspondence: emg_bethgomes@yahoo.com.br
}

\begin{abstract}
RESUMO. Este artigo objetiva refletir acerca de duas grandes questões que envolvem os campesinos e que se constituem como "bandeiras" fundamentais: a primeira é a questão da terra, a segunda é a educação do campo. Toma-se, inicialmente, como objeto de análise as Constituições Federais Brasileiras por entender que tais compõem as visões historicamente construídas acerca do campesino brasileiro, para em seguida iniciar reflexões acerca das propostas da Educação do Campo. Tais reflexões evidenciam as relações entre a construção do que, neste artigo, se denomina como "invisibilidade" das populações campesinas e a constituição de um movimento em prol de uma educação que considere suas especificidades. Tais lutas em relação à constituição de uma educação de qualidade para os sujeitos campesinos vêm garantindo algumas conquistas de modo a torná-los visíveis, em detrimento de uma visão hegemônica que tende a torná-los uma massa amorfa, desconsiderando suas especificidades e saberes.
\end{abstract}

Palavras-chave: Constituições Federais, Movimentos Sociais, Luta, Educação do Campo. 


\title{
Land tenure legislation and countryside education in Brazil
}

\begin{abstract}
This paper aims at reflecting about two great questions concerning rural population; such questions constitute themselves as fundamental fighting pillars: land, and countryside education. Firstly, Brazil's Federal Constitution is taken under analyses, since it represents the official view towards rural population, secondly, reflections are drawn regarding what is suggested concerning Countryside Education. These reflections highlight the relationship between, what is here denominated as "invisibility" regarding rural population, and a movement towards an education that takes under consideration its specificities. The battles for better education for rural communities has guaranteed some achievements, thus making them visible, in detriment of a hegemonic view, which tends to take rural populations as part of a whole, disregarding their specificities and traditional knowledge.
\end{abstract}

Keywords: Federal Constitutions, Social Movements, Fighting, Countryside Education. 


\section{Legislación sobre tenencia de tierras y Educación del Campo en Brasil}

RESUMEN. Este trabajo tiene el objetivo de reflexionar acerca de dos grandes cuestiones que involucran a los campesinos y que se constituyen como banderas fundamentales: la primera es la cuestión de la tierra, la segunda es la educación del campo. Se toma inicialmente como objeto de análisis las Constituciones Federales Brasileñas por entender que tales componen las visiones históricamente construidas acerca del campesino brasileño, para luego iniciar reflexiones acerca de las propuestas de la Educación del Campo. Tales reflexiones evidencian las relaciones entre la construcción de lo que en este artículo se denomina invisibilidad de las poblaciones campesinas y la constitución de un movimiento en favor de una educación que considere sus especificidades. Tales luchas con relación a la constitución de una educación de calidad para los sujetos campesinos vienen garantizando algunas conquistas para hacerlos visibles, en detrimento de una visión hegemónica que tiende a hacerlos como parte del todo, desconsiderando sus especificidades y saberes.

Palabras clave: Constituciones Federales, Movimientos Sociales, Lucha, Educación del Campo. 


\section{Introdução}

A sociedade brasileira construiu e se acostumou a uma invisibilidade das populações do campo. Caso se considere que o "olhar" do outro ajuda o sujeito a se constituir como tal, e que as ideias de movimentos sociais normalmente demandam um tempo para alcançarem a adesão da sociedade em geral, os sujeitos de movimentos campesinos têm desempenhado um duplo esforço.

O primeiro esforço se encaminha no sentido de desconstruir uma representação de campo e de campesino caracterizados pela falta, pelo atraso, pela ignorância. O segundo se amplia no sentido de alcançar a empatia da sociedade para com essas populações, esses lugares e para com o próprio movimento de modo a legitimar os posicionamentos desenvolvidos em seu interior.

Desse modo, tais grupamentos sociais têm buscado "virar o jogo", a partir de formas de organização que alcançam mobilização significativa, demonstrando a capacidade de lutas e reflexões em busca de conquistas no campo social e educacional. Neste artigo, objetiva-se refletir acerca de duas grandes questões que envolvem os campesinos e que se constituem como "bandeiras" fundamentais: a primeira é a questão da terra, a segunda é a educação do campo.
Em relação a questões de terra, desenvolvem-se discussões acerca de discursos legais, tendo como foco as Constituições Federais Brasileiras, no sentido de entender como o Estado tem-se colocado juridicamente em relação à questão da propriedade no país. Essa é uma questão importante, visto que posicionamentos jurídicos que regulamentam a posse de terras implicam visões de sujeitos possuidores de bens, especificando o "lugar" tanto de possuidores, como do Estado no que tange à regulação de direitos a propriedades. Entender como o Estado brasileiro institui(u) posicionamentos com vistas à garantia de construção de políticas de bemestar social, torna-se fundamental, pois esses definem econômica e socialmente o destino das populações.

Entre os direitos fundamentais do homem (a partir da idade moderna), encontram-se àqueles relativos à moradia, à educação, ao lazer, enfim, direitos que emprestam ao homem dignidade e qualidade de vida. Dentre tais, destacou-se o direito à educação. Por isso, a segunda parte deste artigo encaminha-se para discussões relativas à educação do campo, uma vez que além de se constituir como direito fundamental, constitui-se também como uma das maiores reivindicações das 
populações campesinas, conforme se afirmou anteriormente.

\section{As Constituições Federais Brasileiras e a posse de terras}

Ao se pensar o texto das Constituições Federais Brasileiras não se pode negar dois fatos que tiveram influência significativa na produção dessas. São eles a independência da América (1776) e a Declaração dos Direitos Humanos (1789). Esses fatos históricos evidenciam uma perspectiva libertária, calcada no tripé: liberdade, igualdade e fraternidade, reafirmando as ideias iluministas vigentes em todo o mundo.

A Assembleia Nacional Constituinte da França aprovou e votou a Declaração dos Direitos do Homem e do Cidadão, definidora dos direitos individuais e coletivos dos homens (tomada a palavra na acepção de "seres humanos") como universais. Naquele documento, influenciado pela doutrina dos "direitos naturais", os direitos dos homens passaram a universais: válidos e exigíveis a qualquer tempo e em qualquer lugar, pois se amalgamam à própria natureza humana, e a esta se mostram e se incorporam: "Art.1. Os homens nascem e são livres e iguais em direitos. As distinções sociais só podem fundamentar-se na utilidade comum". (Humanos, 2013).
Desta condição de "seres humanos" a lei não excluiu os índios, os negros e os mamelucos que viviam sob a dominação portuguesa, no caso do Brasil: “Art. 2. ${ }^{\circ} \mathrm{A}$ finalidade de toda associação política é a conservação dos direitos naturais e imprescritíveis do homem. Esses direitos são a liberdade, a propriedade, a segurança e a resistência à opressão". (Humanos, 2013).

A partir desses fatos e leis inicia-se, em todo o mundo, especialmente na América, movimentos ligados quer à independência das colônias, quer à libertação de negros e povos escravizados, sendo que em relação a estes a luta se desenvolveu também no sentido de reconhecê-los como "humanos", $\mathrm{Na}$ contramão dessa história popular, os colonizadores portugueses no Brasil passaram a adotar punições severas, condenando à morte aqueles que se atreviam a promulgar a igualdade, liberdade e fraternidade. Paradoxalmente, entretanto, estabelecem-se as legislações de caráter liberal, o que, para a época, significará grandes avanços.

\section{As Constituições Brasileiras} abordam diferentemente a questão da propriedade, cada uma, via de regra, obedecendo a preceitos colocados para os diferentes tempos que as produziram. De acordo com Ferreira (2007), observa-se: 
$\mathrm{Na}$ evolução histórica do constitucionalismo brasileiro, é possível distinguir três fases distintas, cada uma das quais marcada por influência de valores políticos, jurídicos e ideológicos diversos na formalização das instituições em geral- e da propriedade em particular- embora seja inegável a existência de uma incorporação cumulativa dos diferentes influxos. A primeira fase está ligada aos padrões constitucionais inglês e francês do século XIX; a segunda, ao modelo norte-americano; a terceira, ao constitucionalismo de origem alemã vigente no século XX. (Bonavides, 1993, apud Ferreira, 2007, p. 184).

Em 1822, o país se torna independente de Portugal, porém, mantém a grande maioria da população nas correntes do analfabetismo e outra parte na escravidão, provendo a alguns poucos, depois de dois anos, uma Constituição Federal (CF) promulgada e capaz de refletir os ideais liberais vigentes.

A Constituição Federal de 1824, assim como ocorrera na Lei de Terras de 1850, mantém o direito à propriedade, independentemente de seu uso ou não pelo possuidor. Em seu Artigo 179, Inciso XXII determina que:

Art. 179. A inviolabilidade dos Direitos Civis, e Politicos dos Cidadãos Brazileiros, que tem por base a liberdade, a segurança individual, e a propriedade, é garantida pela Constituição do Imperio, pela maneira seguinte. XXII. É garantido o Direito de Propriedade em toda a sua plenitude. $\mathrm{Se}$ o bem público legalmente verificado exigir o uso, e emprego da Propriedade do Cidadão, será elle préviamente indemnizado do valor della. A Lei marcará os casos, em que terá logar esta única excepção, e dará as regras para se determinar a indemnização. (Brasil, 1824).

Como se pode perceber, a Constituição garante o direito à propriedade em sua plenitude, o que implica a continuidade do direito de compra e venda, independentemente do uso da terra ou não. A terra continuava a ser uma propriedade individual da qual seu possuidor poderia dispor livremente, podendo ser requerida pelo Estado, desde que comprovada a necessidade e acertada a indenização ao proprietário.

Essa mesma ideia é mantida na $\mathrm{CF}$ de 1891, cujo Artigo 72, Parágrafo 17 (Seção II - Declaração de Direitos) dispõe:

Artigo 72: "O direito de propriedade mantém-se em toda a sua plenitude, salvo a desapropriação por necessidade ou utilidade publica, mediante indenização previa. As minas pertencem aos proprietários do solo, salvas as limitações que forem estabelecidas por lei a bem da exploração deste ramo de indústria". (Brasil, 1891).

Como houve resistência ao tripé humanitário (liberdade, igualdade e fraternidade), os intelectuais e revolucionários buscaram outros direitos o que teria provocado ao longo do século XIX revoluções e problemas sociais, que assolaram os Estados, ao ponto de lhes 
impor modificações profundas, tornandoos irreconhecíveis e porque não dizer, extintos da forma que anteriormente se afirmaram. Surge o estado social ou do bem-estar social, cuja influência foi identificada, pela primeira vez, no Texto Político Mexicano de 1917, e, posteriormente, na Constituição Alemã, em 1919. À Carta Política Mexicana é atribuída, a primeira dentre todas, a inserção e elevação dos direitos trabalhistas à qualidade de direitos fundamentais, juntamente com as liberdades individuais e os direitos políticos $\left(\operatorname{arts} .5^{\circ}\right.$ e $\left.123^{\circ}\right)$.

A importância desse precedente histórico deve ser salientada, pois na Europa a consciência de que os direitos humanos teriam também uma dimensão social só veio a se firmar após a grande guerra de 1914/1918. A Constituição de Weimar (Alemanha), em 1919, trilhou a mesma via da Carta Mexicana, e todas as convenções aprovadas pela recém-criada Organização Internacional do Trabalho, na Conferência de Washington daquele mesmo ano, pautaram-se por princípios e regulamentações de matérias que já constavam da Constituição Mexicana, tais como: a limitação da jornada de trabalho, o desemprego, a proteção da maternidade, a idade mínima de admissão nos trabalhos industriais e o trabalho noturno dos menores na indústria.

Entre a Constituição Mexicana e a de Weimar Verfassung, eclode a Revolução Russa, um acontecimento decisivo na evolução da humanidade do século XX. O III Congresso Pan-Russo dos Sovietes, de Deputados Operários, Soldados e Camponeses, reunido em Moscou adotou em janeiro de 1918, antes do término da $1^{\mathrm{a}}$ Guerra Mundial, a Declaração dos Direitos do Povo Trabalhador e Explorado. Nesse documento, são afirmadas e levadas às suas consequências, agora com apoio da doutrina marxista, várias medidas constantes da Constituição Mexicana, tanto no campo socioeconômico quanto no político.

Todos esses novos referenciais alteraram a concepção do direito de propriedade, passando a reconhecer a existência de deveres do proprietário em relação à sociedade. E ainda por temor ao alastramento dos ideais marxistas agregou-se à propriedade o princípio da função social, que alguns estudiosos sustentam e atribuem sua formulação a Augusto Comte e sua postulação a León Duguit.

Foi o mesmo León Duguit, quem afirmou de forma mais veemente que a propriedade teria de deixar de ser somente um direito subjetivo do indivíduo para se 
converter em função social, restando ao seu detentor a obrigação de empregá-la para o crescimento da riqueza social e para a interdependência social ${ }^{\mathrm{ii}}$.

No Brasil, a Constituição de 1934 seguindo os ideais mexicanos e europeus, trouxe importante inovação, ao afirmar, ainda que de modo indireto, a função social da propriedade. Conforme dispõe em seu artigo 113: “Art. 113: É garantido o direito de propriedade, que não poderá ser exercido contra o interesse social ou coletivo, na forma que a lei determinar. A desapropriação por necessidade ou utilidade pública far-se-á mediante previa e justa indenização”. (Brasil, 1934).

Porém, em 1937, no Texto Constitucional, a noção de que a propriedade deveria atender sua função social, $\operatorname{logo}$ se retraiu e na lição de Ferreira (2007, p. 186) a Constituição de 1937 "marcou um retrocesso" em relação ao texto anterior, pois no Art. 122, Inc. 14, apenas assegurou o direito à propriedade e fez vaga referência que seu conteúdo e limites seriam definidos nas leis que regulassem o seu exercício, nada explicitando em relação à função social da terra.

Na Constituição de 1946, apesar da diversidade de correntes de pensamento representadas na Constituinte de 1946, predominavam as ideias conservadoras às progressistas ou socialistas (Motta, 1997). A composição social e profissional de seus membros, "congregava maciçamente titulares de propriedades". Mais de 90\% dos constituintes eram pessoalmente proprietários, ou vinculados por seus parentes próximos - pais e sogros - à propriedade, sobretudo imobiliária. Compreende-se que desse "corpo coletivo jamais poderia brotar texto oposto à propriedade". (Baleeiro, 1997). A constituição de 1946, após a omissão da Carta de 1937, estabeleceu, de modo explícito, em seu artigo 147, que: "o uso da propriedade será condicionado ao bemestar social. A Lei poderá, com observância do disposto no artigo 141, parágrafo 16 , promover a justa distribuição da propriedade, com igual oportunidade para todos". (Brasil, 1946). E por referência ao art. 141, §16 tem-se que:

Art. 141. A Constituição assegura aos brasileiros e aos estrangeiros residentes no país a inviolabilidade dos direitos concernentes à vida, à liberdade, à segurança individual e à propriedade, nos termos seguintes: $\S$ 16: É garantido o direito de propriedade, salvo o caso de desapropriação por necessidade ou utilidade pública, ou por interesse social, mediante prévia e justa indenização em dinheiro. Em caso de perigo iminente, como guerra ou comoção intestina, as autoridades competentes poderão usar da propriedade particular, se assim o exigir o bem público, ficando, todavia, assegurado o direito a indenização ulterior. (Brasil, 1946). 
O Artigo citado constitui um marco jurídico, porque prevê a desapropriação por interesse social e, sobretudo, porque busca assegurar a justa distribuição e igual oportunidade de acesso à propriedade. Pela primeira vez, passou-se a exigir do proprietário não somente uma abstenção, um "não-fazer", mas uma teia de atos positivos, concretos, de exploração econômica do imóvel rural. A propriedade passou a ser um direito-dever, em nosso direito positivo (Loureiro, 2003).

As constituições de 1967 e a emenda Constitucional de 1969, não obstante o ambiente político repressivo em que foram geradas, apresentam de modo claro, como finalidade da ordem social, realizar $\mathrm{o}$ princípio da função social da propriedade (art. 157, III), regulando inclusive a desapropriação da propriedade territorial rural. Essa matéria é tratada também no artigo 153 como direito inviolável da pessoa humana, ao lado dos direitos à vida, à liberdade e à segurança. Pela primeira vez, efetivamente a propriedade é tratada tanto no capítulo dos direitos e garantias individuais quanto no título da ordem econômica e social, o que representa uma mudança profunda no conceito do instituto (Ferreira, 2007).

Entretanto, essa preocupação deve ser vista em seu contexto de criação. Datam desse período, pelo menos duas grandes proposições em relação à ocupação de terras: a primeira, a ocupação da Região Norte do país, inclusive a construção da Rodovia Transamazônica, cujos preceitos seguiam as ideias colocadas a partir da "Revolução Verde". Assim, sob o pretexto de produção de alimentos em larga escala, para acabar com a fome mundial, justifica-se a ocupação (a partir da comercialização) das terras ao norte. Novamente, porém, as terras são "vendidas", financiadas a longo prazo para fazendeiros e tinham como propósito a produção em larga escala: retoma-se a monocultura com vistas à exportação e a ocupação de grandes extensões de terras, ocorrendo a "re-inauguração" de latifúndios.

Nessa direção, quando se busca entender a preocupação com a função social da terra estabelecida na Constituição Federal de 1967 e no Ato Institucional de 1969, ou seja, em um contexto ditatorial, faz-se necessário que sejam pensados os contextos que produziram tais discursos. Em primeiro lugar, o financiamento dessas “políticas públicas" teve apoio no "Grupo Rockfeller", que, a partir desse momento expandiu seu mercado consumidor, fortalecendo a corporação com vendas de pacotes de insumos agrícolas, principalmente para países em 
desenvolvimento como Índia, Brasil e México.

Foram financiadas pesquisas com vistas à criação de sementes mais resistentes e próprias para os diferentes tipos de solos, que, "enriquecidos" fortemente por adubação química realmente aumentaram a produção de alimentos, porém esse aumento não significou a erradicação da fome, visto que seu consumo alcançou apenas as populações de países mais ricos. Aos países pobres como o Brasil restaram para grandes proprietários a mecanização da lavoura, mas para pequenos proprietários as dívidas, cujo recurso foi entregar a terra como pagamento pelo não alcance de metas traçadas. Veja-se o texto da Lei:

Art. 157- A ordem econômica tem por fim realizar a justiça social, com base nos seguintes princípios:

II- valorização do trabalho como condição da dignidade humana;

III- função social da propriedade;

IV- harmonia e solidariedade entre os fatores de produção;

$\mathrm{V}$ - desenvolvimento econômico;

$\S 3^{\circ}$ - A desapropriação de que trata o $\S 1^{\circ}$ é da competência exclusiva da União e limitar-se-á às áreas incluídas nas zonas prioritárias, fixadas em decreto do Poder Executivo, só recaindo sobre propriedades rurais cuja forma de exploração contrarie o disposto neste artigo, conforme for definido em lei. $\S 4^{\circ}-\mathrm{A}$ indenização em títulos somente se fará quando se tratar de latifúndio, como tal conceituado em lei, excetuadas as benfeitorias necessárias e úteis, que serão sempre pagas em dinheiro.
$\S 55^{\circ}-$ Os planos que envolvem desapropriação para fins de reforma agrária serão aprovados por decreto do Poder Executivo, e sua execução será da competência de órgãos colegiados, constituídos por brasileiros, de notável saber e Idoneidade, nomeados pelo Presidente da República, depois de aprovada a escolha pelo Senado Federal.

$\S 55^{\circ}-\mathrm{O}$ Presidente da República poderá delegar as atribuições para desapropriação de imóveis rurais, por interesse social, sendo-lhe privativa a declaração de zonas prioritárias.

$\S 6^{\circ}$ - Nos casos de desapropriação, na forma do $\S 1^{\circ}$ do presente artigo, os proprietários ficarão isentos dos impostos federais, estaduais e municipais que incidam sobre a transferência da propriedade desapropriada. (Brasil, 1967).

Ato institucional $\mathrm{n}^{\circ} 9$ de 25 de abril de 1969:

CONSIDERANDO, ainda, que a Reforma Agrária, para a sua execução, reclama instrumentos hábeis que implicam alterações de ordem constitucional, resolve editar o seguinte Ato Institucional:

Art. $1-\mathrm{O} \S 1^{\circ}$ do art. $157 \mathrm{da}$ Constituição Federal passa a vigorar com a seguinte redação:

Art. 157 - (omissis)

$\S 1^{\circ}$ - Para os fins previstos neste artigo a União poderá promover a desapropriação da propriedade territorial rural, mediante pagamento de justa indenização, fixada segundo os critérios que a lei estabelecer, em títulos especiais da dívida pública, com cláusula de exata, correção monetária, resgatáveis no prazo máximo de vinte anos, em parcelas anuais sucessivas, assegurada a sua aceitação, a qualquer tempo, como meio de pagamento de até cinquenta por cento do imposto territorial rural e como pagamento do preço de terras públicas.

Art. $2^{\circ}-$ É substituído o $\S 5^{\circ}$ do art. 157 da Constituição federal pelo seguinte: 
$\S 5^{\circ}-$ O Presidente da República poderá delegar as atribuições para desapropriação de imóveis rurais, por interesse social, sendo-lhe privativa a declaração de zonas prioritárias. (Brasil, 1969).

Deve-se ressaltar ainda que foram os militares, em 30 de novembro de 1964, no governo do presidente Marechal Humberto Castelo Branco, que instituíram a primeira Lei de Reforma Agrária no Brasil, a Lei de $\mathrm{n}^{\circ}$ 4504, também conhecida como "Estatuto da Terra".

O Estatuto da Terra surgiu da necessidade de distribuição de terras; construiu um conceito de campo, determinou os níveis de produtividade e caracterizou o uso social da terra. Não há como negar que o Estatuto apresentou caráter inovador, introduziu novos conceitos ligados à questão agrária. Foi através do Estatuto que se mensurou o minifúndio e o latifúndio. Essa mensuração se daria através dos módulos fiscais, que variavam de acordo com a região, sendo a partir de 15 módulos considerada latifúndio, logo, passível de desapropriação para fins de reforma agrária.

Outra caracterização refere-se aos níveis de produtividade. Para essa, foram traçadas as unidades mínimas de produção por módulo rural a fim de caracterizá-las como produtivas ou improdutivas (Brasil, 1964). Outra inovação deste Diploma Legal foi a definição de função social da terra, estatuído no Título I - Disposições Preliminares, Capítulo I - Princípios e Definições, que em seu $\S^{\circ}$ do artigo $2^{\circ}$ conceitua a função social da seguinte maneira (Brasil, 1964):
Art. $2^{\circ}-$ (omissis)
$\S 1^{\circ}-$ A propriedade da terra desempenha integralmente a sua função social quando, simultaneamente:
a) favorece $\mathrm{o}$ bem-estar dos proprietários e dos trabalhadores que nela labutam, assim como de suas famílias;
b) mantém níveis satisfatórios de produtividade;
c) assegura a conservação dos recursos naturais;
d) observa as disposições legais que regulam as justas relações de trabalho entre os que a possuem e a cultivem.

Apesar de o Estatuto da Terra parecer, por suas definições, uma possibilidade de mudança na estrutura fundiária, ele possui uma dualidade entre a questão distributiva da terra, representada pela reforma agrária e a modernização do campo, sobrepondo o caráter econômico ao social (Filho \& Fontes, 2009). Essa dicotomia entre o social e o econômico favoreceu às grandes propriedades, que contavam com maiores facilidades de modernização do campo e acesso a crédito.

Apesar do caráter progressista do Estatuto da Terra e da sinalização de transformações importantes no âmbito da questão agrária brasileira, pode-se afirmar que esse não saiu do papel e a reforma 
agrária segue sem acontecer no país. A política dos governos militares reduziu-se a esporádicos projetos de colonização, principalmente na região amazônica (Silva, 1997).

Daí retomar a "advertência" de Stédile (1997) da "não" necessidade de aprovar e legislar para que a reforma agrária aconteça, bastando para tanto aplicar o cumprimento das leis que já existem (Stédile, 1997; 2002).

Como resultante do processo de redemocratização e de lutas dos movimentos sociais, cada vez mais organizados, em outubro de 1998, admitido novo Texto Político, não se deu nenhuma inovação em relação à Lei 4.504. Pode-se dizer até que houve retrocessos, pois, a nova constituição acabou por legitimar o "latifúndio produtivo", porém se omitindo a regulamentar o artigo que prevê a desapropriação de terras maiores que $\mathrm{o}$ limite máximo de módulos fiscais, projetando "vida longa" ao latifúndio.

A verdade é que até os dias atuais os níveis de produtividade por módulo fiscal, se mantêm intactos aos padrões editados em 1964 (Stédile, 2002). Também vale ressaltar que foram implementadas algumas medidas provisórias e algumas emendas constitucionais, entretanto nada de relevante no que diz respeito a transformações

consideráveis

na disposição legislativa fundiária no Brasil.

Do ponto de vista legal e político as ações voltadas à desconcentração de terras, durante a década de 1990, não apresentaram transformações consideráveis. No plano econômico, a expansão do agronegócio, fruto da globalização e reabertura econômica, muito contribuiu para a intensificação da concentração de terras e diminuição do número de estabelecimentos rurais (Oliveira, et al., 2005).

Já no plano infraconstitucional, merece destaque o Inciso XXII do art. $5^{\circ}$, que estabelece como direito fundamental à propriedade privada: "XXII - é garantido o direito de propriedade". (Brasil, 1988). E mais garantias tem-se do $\$ 4^{\circ}$ do art. 60, que estabelece garantia dupla à propriedade: "Não será objeto de deliberação a proposta de emenda tendente a abolir." (Brasil, 1988).

Isso significa que, enquanto a atual Constituição se mantiver em vigência, será impossível a supressão desse direito. Nenhum outro direito fora tratado pela Constituição Federal com tanta segurança e fundamento. Já para a propriedade rural, o art. 186 da Constituição Federal (Brasil, 1988) estipula que:

Art. 186. A função social é cumprida quando a propriedade rural atende, simultaneamente, segundo critérios e 
graus de exigência estabelecidos em lei, aos seguintes requisitos:

I- aproveitamento racional e adequado;

II- utilização adequada dos recursos naturais disponíveis e preservação do meio ambiente;

III- observância das disposições que regulam as relações de trabalho;

IV- exploração que favoreça o bemestar dos proprietários e dos trabalhadores.

Assim, a propriedade rural cumpre sua função social se os empregados estiverem em situação condizente com a legislação, os recursos naturais da propriedade não forem utilizados de maneira abusiva, entendendo o Texto Político que a propriedade está dentro dos parâmetros legais constitucionais. Também se acham estendidos no Texto Político hipóteses para um melhor aproveitamento da propriedade, podendo ser objeto de reforma agrária, se por esta se interessar, quer pela utilidade que lhes será reservada, quer por necessidade pública que a propriedade possa vir a possuir.

Em ambos os casos não se tratará de compra, mas de expropriação ou desapropriação, oportunidades em que serão estipuladas indenizações prévias e justas, que a atual Constituição Federal trata em Art. 184:

Art. 184. Compete à União desapropriar por interesse social, para fins de reforma agrária, o imóvel rural que não esteja cumprindo sua função social, mediante prévia e justa indenização em títulos da dívida agrária, com cláusula de preservação do valor real, resgatáveis no prazo de até vinte anos, a partir do segundo ano de sua emissão, e cuja utilização será definida em lei. (Brasil, 1988).

Nossos legisladores, salvo exceções, não fazem render suas obras legislativas em benefício da justiça criando sempre um hiato entre aquilo que é justiça (bem a ser distribuído para todos) e aquilo que é lei (matéria delimitada destinada a determinado número de pessoas).

A partir da exposição anterior, espera-se ter minimamente apresentado, a partir das legislações expressas uma visão panorâmica de formas de tratamento da propriedade no Brasil. Do Império à República, é fato que tal matéria tem sido tratada a partir de um viés mais propenso ao Liberalismo, tendo o Estado pouca preocupação social, o que de certa forma, "justifica" que ainda no século XXI a Reforma Agrária não tenha ocorrido de fato.

\section{Campesinos e a luta pela educação:}

Os movimentos sociais ligados ao campo entendem que o direito e o acesso à terra necessitam se ancorar em outros direitos e outras possibilidades de acesso. Por isso, principalmente a partir das décadas de 1980/1990, eles vêm construindo um conjunto de pressupostos e propostas que consideram os vários 
aspectos de uma vida de qualidade e dignidade. No interior dessa pauta de reivindicações, direitos concernentes à educação ganham vulto, no sentido de garantir não apenas a posse de terras, mas de tornar os lugares onde vivem dotados de qualidade, de modo a garantir a permanência desses povos no campo.

Uma de suas lutas passa a ser, pois, a luta pela educação; vista como um direito de todos e como uma forma de libertação de si e de outros. E, nesse sentido, os povos do Campo passam a desenvolver lutas que os colocam como protagonistas da própria história. Para tanto, várias são as conferências, os encontros e as discussões ocorridas cotidianamente no interior das várias comunidades campesinas, no interior de escolas e universidades e no órgão máximo de Educação, o Ministério de Educação e Cultura.

Reflexões acerca de quem são esses sujeitos e que educação buscam construir, constituem-se como objeto de reflexão neste artigo. A construção de diretrizes educacionais é resultado de debates coletivos que oportunizaram a tomada de consciência, por parte desses grupos sociais sobre si e sobre os outros. Entretanto, para que tais debates pudessem ocorrer de forma crítica e consciente, tornou-se fundamental uma explicitação/definição de si mesmos.
Os atos de nomear e definir implicam uma ação que busca reconhecer a si mesmo. Sem um nome e sem uma definição clara do que se é, pode ocorrer um truncamento de informações, impedindo a construção de pertencimento, de reconhecimento de determinado grupo. Nesse caso, a nomeação/definição visou esclarecer a diversidade, além de identificar traços de união entre o grupo. A definição vem expressa a partir do Decreto 7.352/2010 que afirma:

$\S 1^{\circ}$ Para os efeitos deste Decreto, entende-se por:

I- populações do campo: os agricultores familiares, os extrativistas, os pescadores artesanais, os ribeirinhos, os assentados e acampados da reforma agrária, os trabalhadores assalariados rurais, os quilombolas, os caiçaras, os povos da floresta, os caboclos e outros que produzam suas condições materiais de existência a partir do trabalho no meio rural. (Decreto $\mathrm{n}^{\circ}$ 7.352/2010, citado por Molina e Freitas, 2011, p. 21).

Paralelamente à definição de si mesmos, cumpria também organizar as propostas relativas à educação construídas e constituídas no interior de lutas dessas populações. Assim, princípios são construídos e consolidados, pois não se quer qualquer educação. Não se quer principalmente uma educação transposta da cidade para o campo. Recusa-se a até então denominada "Educação Rural”, visto que essa se organizou em uma perspectiva 
excludente e de "conformação" social, que não dava conta de abarcar a diversidade dessas populações, mas principalmente não dava conta de entender os povos do campo a partir de seu protagonismo.

A recusa ao "nome" (educação rural) significou a ruptura com uma visão calcada em uma assimetria social e educacional em busca de construção de uma educação baseada na participação coletiva. Passou-se a denominar "Educação do Campo", o que ressalta a apropriação coletiva dos sujeitos do campo. A Educação passa a se organizar como necessidade para o atendimento de demandas (aprendizagens, valorização de formas de vida, das culturas desses povos), e principalmente se constrói como uma educação em que os campesinos se apropriam dela, com o objetivo de constituírem a si mesmos e se verem reconhecidos como sujeitos históricos e sociais, sem perderem de vista a universalização dos conhecimentos como um direito social.

Ainda é importante nomear (se não todos) alguns desses movimentos que têm participado dessa construção e organização política a fim de garantir conquistas para os povos do campo. De acordo com Martins (2013, p. 183), várias são as organizações, movimentos, instituições que têm contribuído para, sejam pensadas a Educação do Campo:
Entre os movimentos sociais que compõem a Educação do Campo, o MST, indubitavelmente, se destaca. Redes regionais ou locais, que assumem características de movimentos sociais, como a Rede de Educação do Semiárido Brasileiro (RESAB). É possível enfatizar também o Movimento dos Atingidos pelas Barragens (MAB), o Movimento das Mulheres Camponesas (MMC), a Confederação dos Trabalhadores da Agricultura (CONTAG), o Movimento dos Pequenos Agricultores (MPA), as Associações Regionais das Casas Familiares Rurais (ARCAFARs), e sua expressão nacional, a União Nacional das Escolas Famílias Agrícolas do Brasil (UNEFAB), a Federação Nacional dos Trabalhadores e Trabalhadoras na Agricultura Familiar (FETRAF). (Martins, 2013, p. 183).

Ressalte-se a importância da "I Conferência Nacional: Por uma Educação Básica do Campo", ocorrida em Brasília (1996), que significou um marco organizacional, teórico e metodológico para a construção e implementação de Políticas Públicas para essas populações. Foi também, principalmente a partir desse momento, que as lutas campesinas ganharam maior visibilidade em nível nacional em sua luta para a garantia de direitos desses povos.

A I Conferência Nacional: Por uma Educação Básica do Campo pode ser considerada um marco importante. Trata-se de um processo de reflexão e mobilização do povo em favor da educação que considere nos seus conteúdos e na metodologia, o específico do campo. Esse processo 
foi iniciado como consta na Coleção (números 1 a 6) Por uma educação básica do campo, no final do I Encontro Nacional de Educadores e Educadoras da Reforma Agrária (I ENERA), promovido pelo Movimento dos Trabalhadores Rurais Sem Terra (MST), em julho de 1997, em Brasília, em parceria com diversas entidades, como a Universidade de Brasília (UnB), o Fundo das Nações Unidas para a Infância (Unicef), a Organização das Nações Unidas para a Educação, Ciência e Cultura (Unesco) e a Conferência Nacional dos Bispos do Brasil (CNBB). O trabalho coletivo dessas entidades e instituições partiu do pressuposto do que seria específico da educação do campo levando em conta a cultura, as características, as necessidades e os sonhos dos que vivem no e do campo. (Zen \& Foerste, 2006, p. 1).

Parafraseando Caldart (2009), reafirma-se que o país se encontra em um momento de crise. Crise que alcança aspectos estruturais, políticos, sociais, educacionais, identitários, éticos... enfim, essa lista poderia ser infinita; porém, o que se quer aqui reafirmar é que esse termo (crise) e mais que isso a sua vivência têm se tornado uma constante na vida de brasileiros, propalada quer em meios midiáticos, quer em conversas ordinárias, quer em meios políticos... mas, destaquese, que a educação do campo também tem se defrontado com "crises", que se revelam, dentre outras, no fechamento de escolas do campo.

Convive-se contemporaneamente com uma perspectiva que coloca a educação do campo no "fio da navalha" (Caldart, 2009), evidenciado por antagonismos que, por um lado, tornam propenso o fechamento de escolas existentes no campo, sob alegação de um excesso de despesas em relação à manutenção de tais. Mas por outro lado, também se registram "ganhos" com aumentos significativos de oferta de formação superior e/ou profissional que deve alcançar os povos do campo.

Nesse interstício entre o fechamento e a construção de políticas públicas que propiciam o atendimento aos povos do campo, que papel exerce o Estado? Como explicar e entender essa aparente dicotomia que insiste em "residir" no próprio Estado? Que aspectos têm determinado tais ações por parte do Estado? E, de que formas as populações do campo têm se organizado para tentar reverter essas ações, de modo a dar continuidade às políticas de formação e superação de desigualdades? $\mathrm{O}$ fio da navalha se torna mais afiado.

Refletir sobre tais questões é ponto fundamental para se pensar os caminhos e possibilidades relacionados à continuidade e ampliação da educação do campo. Os dados do censo escolar do INEP - Instituto Nacional de Estudos e Pesquisas Educacionais Anísio Teixeira, indicam que o número de escolas que têm sido fechadas vem crescendo nos últimos anos. Esses 
dados indicam o fechamento de mais de 37 mil escolas do campo nos últimos 15 anos, sendo as regiões Norte e Nordeste, as “campeãs” com cerca de 1986 escolas, seguidas pelas regiões Sul e Sudeste com 588, apenas no ano de $2014^{\text {iii }}$.

Entretanto, outros dados evidenciam a existência de um crescimento em termos de cumprimento de políticas públicas em relação a processos de formação das populações campesinas. Essas populações vêm pressionando de diferentes formas a União de modo a verem cumpridos direitos constitucionais conquistados. Isso implica o crescimento de oferta educacional para as populações campesinas, embora não deem conta de suprir as demandas, principalmente em relação à formação de professores, conforme demonstrado em Hage, Silva e Brito (2016, p. 155-156):

A partir do Decreto 7.352/2010 (Brasil, 2010), que instituiu a Política Nacional de Educação do Campo e definiu metas específicas para a formação de educadores, o MEC lançou o Edital n ${ }^{\circ} 02$ de 31/08/2012 (Brasil, 2012), vinculado à SESu/Setec/Secadi/MEC, que aprovou 42 projetos do Procampo apresentados pelas universidades e os institutos federais, para ofertar, cada um deles, 300 vagas regulares na modalidade presencial durante três anos no Curso de Licenciatura em Educação do Campo, totalizando 15.120 vagas para a formação inicial de professores dos territórios rurais. Nesse edital, foram incluídas 15 vagas de concurso para docentes e três para servidores em cada um dos projetos, totalizando 630 vagas de docentes permanentes e 126 de servidores efetivos para atuação específica nos Cursos de Licenciatura em Educação do Campo. (Grifos meus)

Afiando ainda um pouco mais o fio da navalha em que se encontram as populações do campo em suas lutas pela conquista de processos educacionais, temos que:
os dados revelam que, das 29.830.007 pessoas que vivem no campo no Brasil (IBGE, 2010), somente $21 \%$ acessam a escola, pois existem apenas 6,3 milhões de matrículas nas escolas rurais, segundo o Censo Escolar do INEP (2011). No âmbito da formação de educadores, os dados disponibilizados Censo Escolar de 2011 indicam que, dos 342.845 professores que atuam no campo no Brasil, quase a metade- 160.317- não possui educação superior (46,7\%), e, destes, 156.190 possuem o Ensino Médio $(97,4 \%)$ e 4.127 possuem apenas o Ensino Fundamental $(2,6 \%)$. (Hage, Silva \& Brito, 2016, p. 160).

De um lado, a diminuição de um público cujas idades requerem sua presença em escolas de educação básica; as quais estão sendo fechadas, sob alegação de ausência de público; de outro o aumento de oferta no que tange à formação de professores; como justificar a existência de uma política pública (do ponto de vista quantitativo) que garanta o acesso e a continuidade de tal? Não existiriam nesse contexto, pelo menos duas perspectivas que se antagonizam? É um pouco nessa 
direção que se encaminham as reflexões a serem apresentadas no âmbito deste trabalho.

Nessa profusão de informações que parecem contraditórias e nos fazem pender ora para o consentimento, a adesão de continuidade da Educação do Campo, ora justificam as ações governamentais, com o fechamento de escolas em espaços campesinos, reasseveram o "fio $\mathrm{da}$ navalha" referenciado por Caldart. Faz-se, então, necessário refletir um pouco mais sobre essas situações. Uma das possibilidades para se entender essa aparente dicotomia pode ser evidenciada a partir de diferentes concepções de campo, considerando as diferentes formas de produção, de trabalho e variadas relações entre homens e mulheres reais com o espaço campesino. Isso implica ainda que não há como pensar uma escola do campo sem que seja pensado o próprio campo. Que modelos de sociedade se encontram implícitos em cada um dos posicionamentos?

Não se quer, nos limites deste trabalho, dicotomizar as relações, visto que as opções teóricas adotadas partem não do antagonismo, mas, sobretudo, optou-se por um pensamento que se encaminha em perspectiva dialética, pois, acredita-se que tal pode possibilitar a ampliação de olhares sobre um determinado fenômeno.
Entretanto, algumas considerações/reflexões podem ser apontadas no intuito de ampliar o entendimento acerca de questão tida como controversa e complexa que é a educação do campo. Uma primeira reflexão há que ser apontada. Não há como pensar a educação do campo sem que sejam pensadas concepções e paradigmas de sociedade, de Estado e de projetos de sociedade que se querem/devem construir.

De posse desse argumento inicial, é permitido que sejam pensados, primeiramente, que os discursos produzidos para as questões educacionais campesinas apresentam diversidade, construindo interpretações para tais, de acordo com concepções de campo e de educação do campo. Caso se pense em uma perspectiva hegemônica, o quantitativo de pessoas não justifica investimentos de vulto na educação dessas populações. Na perspectiva do agronegócio e da agroindústria, o campo pode ficar "sem sujeitos", porque se torna o lugar de uso de técnicas para grandes produções. As pessoas iriam apenas trabalhar (de forma assalariada) nesse espaço rural.

Nessa perspectiva, considera-se campo como um território espacial destinado à produção com vistas principalmente à exportação, que, no dizer de Aquino (2013, p. 31) caracteriza-se 
como "as grandes propriedades, grilos, grileiros, exploração do trabalho, grandes empresas capitalistas, crimes ambientais, mecanização intensa, superprodução, improdutividade, especulação fundiária, violência contra pessoa e concentração do poder econômico e político".

Entretanto, pode-se pensar o campo e, por conseguinte, o trabalho no campo como uma maneira de construção de territorialidades, no sentido que Raffestin (1993) empresta ao termo. Afirma esse autor:

de acordo com nossa perspectiva, a territorialidade assume um valor bem particular, pois reflete o multidimensionamento do "vivido" territorial pelos membros de uma coletividade, pela sociedade em geral. Os homens "vivem" ao mesmo tempo, o processo territorial por intermédio de um sistema de relações existenciais e/ou produtivistas. (Raffestin, 1993, p. 158).

Nesse sentido, o termo ganha amplitude a partir da consideração de relações tridimensionais espaço/tempo/sujeitos e o próprio território ganha uma identidade não em si mesmo, mas a partir dos sujeitos coletivos que nele vivem e o fazem produzir. Considera-se, pois, nessa perspectiva, um conjunto de relações de trabalho, de não trabalho, de culturas, de relações sociais e simbólicas produzidas e vividas pelo homem consigo, com o outro e com os espaços que ele vai construindo. Essa é a concepção que se adota no presente trabalho, que se configura como um espaço de existência/resistência para determinados grupos sociais.

Esses dois modelos existentes pressupõem uma diferença nas relações de trabalho e com a terra, pois conforme demonstra Aquino (2013): “... as grandes propriedades dedicam-se à exportação, as médias e pequenas são responsáveis por cerca de $70 \%$ da produção de alimentos consumidos ... Entretanto, recebem apenas $25 \%$ do financiamento destinado à agricultura, e empregam $77 \%$ do pessoal... (IBGE, 2009).”(Aquino, 2013, p. 30).

Esses dois modelos existentes permitem que seja entendida a polaridade das ações impetradas. De um lado uma concepção de campo calcada em valores do agronegócio, sem maiores preocupações com o meio ambiente cujo objetivo é uma produção em larga escala, com vistas à lucratividade e exportação. De outro, uma concepção ligada à agricultura familiar e um estilo de vida camponesa, agroecológica, cujo objetivo é viver da e na terra, fazendo-a produzir de forma sustentável.

Tais modelos pressupõem propostas diferenciadas para a educação. No primeiro, são suficientes as formas de educação que deem conta de produzir uma 
relativa apropriação de conhecimentos, de técnicas e de algumas tecnologias pelos trabalhadores de modo que possam cumprir a contento suas atividades. $\mathrm{O}$ segundo busca construir uma educação em que os trabalhadores campesinos se apropriem de fato de conhecimentos, saberes, técnicas e tecnologias em função de garantir uma equidade social para todos os brasileiros.

Projetos de sociedade diferenciados exigem a definição do lugar de fala, exigindo clareza e objetividade de "posturas". Define-se, nessa perspectiva, uma opção teórica que coaduna com os ideais dos campesinos e não àqueles para os campesinos. Cabe que se coloquem discussões acerca de concepções de educação do campo, de campo e de trabalho, ou no dizer de Caldart (2009):

Podemos dizer sobre a Educação do campo, parafraseando Emir Sader (prefácio a Mészáros, 2005, p. 15) que sua natureza e seu destino estão profundamente ligados ao destino do trabalho no campo e, consequentemente, ao destino das lutas sociais dos trabalhadores e da solução dos embates de projetos que constituem a dinâmica atual do campo brasileiro, da sociedade brasileira, do mundo sob a égide do capitalismo em que vivemos. E ainda que 'muitos não queiram', esta realidade exige posição (teórica sim, mas, sobretudo, prática, política) de todos os que hoje afirmam trabalhar em nome da Educação do campo. (Caldart, 2009, p. 36-37).
Pensa-se também, valendo-se dos ensinamentos de Caldart (2009) que a educação do campo surgiu em um determinado momento e contexto e não pode ser compreendida em si mesma, ou apenas no mundo da educação ou a partir dos parâmetros teóricos da pedagogia. Ela é um movimento real de combate ao "atual estado de coisas". (Caldart, 2009, p. 40). Assim, trata-se um movimento em que se consideram as diferentes práticas, saberes e instrumentos construídos/utilizados por campesinos, que diante de situações concretas de existência buscaram construir processos de resistências diante de um quadro nada favorável com os quais conviviam.

Nesse contexto, consideram-se os movimentos sociais como os sujeitos que protagonizaram um conjunto de ações possibilitando a construção de uma educação do campo. E esse protagonismo é um dos princípios que direcionam as ações, os olhares e que determinam o lugar dos sujeitos individuais e coletivos do campo, e que busca retirar-lhes a invisibilidade historicamente construída. Se na construção inicial desse movimento, optouse por outra denominação (educação do campo $\mathrm{X}$ educação rural), tal definição materializada em uma opção linguística (“do") que indica a apropriação de outro lugar: a educação é "do" campo no sentido 
de garantir a posse, mas, sobretudo, de protagonismo, de pertencimento, logo de identidade.

Certamente uma das principais construções de cunho político dos movimentos sociais campesinos é a questão identitária. Se, historicamente, os campesinos foram confinados a uma invisibilidade, a busca do protagonismo deveria resistir a partir também de um processo de reconhecimento dessas identidades. Assim, é importante reafirmar que as lutas sociais desenvolvidas pelos movimentos cunham como processos formativos não apenas os processos escolares formais, mas têm nas lutas sociais formas de aprendizagem que reverberam em proposições educativas escolarizadas. Nesse sentido, inverte-se uma lógica hegemônica e tradicionalmente vivenciada pelas escolas.

Tais posicionamentos políticos adotam perspectivas gramscinianas cujos pressupostos teóricos tornam cada sujeito alguém a ser formado no trabalho, na luta, mas que a partir de reflexões individuais e coletivas também se torna formador de si e do outro; os sujeitos se formam coletivamente (Freire, 1987). E são essas experiências formadoras da luta coletiva que os campesinos querem também ver reconhecidas nas escolas, as quais devem tomá-las como elemento "provocador" da construção de conhecimentos.

Ainda, a luta ganha uma essência dialógica com a pedagogia num permanente movimento de reflexão das experiências de resistência camponesa, que visa garantir sua existência. Entendendo a palavra resistência em sua acepção etimológica, relativa à continuidade de existência, mas que, no contexto, extrapola o puro existir, referindo-se ao existir com qualidade de vida. Realce-se, pois, a etimologia dessas palavras em suas semelhanças, enfatizando o campo semântico possibilitado, para formas de ser e de estar em algum lugar, de modo a possibilitar a existência, isto é, de modo a "possibilitar a vida". Eis aí uma das essências construídas pelos movimentos sociais como sujeitos coletivos em luta pelo acesso à educação.

As formas de organização social e as mobilizações dessas populações permitiram, a partir da I Conferência Nacional "Por uma Educação do Campo" a continuidade e a constante ocorrência de Fóruns, Conferências, Encontros, que se caracterizam por momentos cuja atuação política buscou e busca constituir legislações e programas de formação que deem conta de se constituírem como marcos regulatórios (referenciais) para 
organização de escolas campesinas. Dentre tais, destaquem-se:

Diretrizes Operacionais para a Educação Básica nas Escolas do Campo, aprovadas por meio da Resolução $n^{\circ} \quad 1 / 2002 \quad \mathrm{CEB} / \mathrm{CNE}$ (Brasil, 2002). ... Do mesmo modo, o Decreto $\mathrm{n}^{\circ}$ 7.352/2010 (Brasil, 2010), que dispõe sobre a política de educação do campo e o Pronera, define como um dos princípios "o desenvolvimento de políticas de formação de profissionais da educação para o atendimento da especificidade das escolas do campo, considerando-se as condições concretas da produção e reprodução social da vida no campo" (Brasil, 2010, art. $2^{\circ}$, III). A partir desses marcos regulatórios, diversos programas: ... O Programa Nacional de Educação na Reforma Agrária; o Programa Escola Ativa(2012); o Programa Escola da Terra (2013); O Programa Projovem Campo Saberes da Terra; o Programa de Apoio à Formação Superior em Licenciatura em Educação no Campo; o Programa de Iniciação à Docência para a Diversidade no âmbito do Programa Institucional de Bolsa de Iniciação à Docência. No ano de 2012, como desdobramento do Decreto $\mathrm{n}^{\mathrm{o}}$ 7.352/2010 (Brasil, 2010), a presidente Dilma Rousseff lançou o Programa Nacional de Educação do Campo (Pronacampo). (Brasil, 2012). (Hage, Silva \& Brito, 2016, p. 152154).

Ainda se torna importante ressaltar que os processos formativos têm optado pela adoção, do ponto de vista metodológico, pela Pedagogia da Alternância, ressaltando as características referentes aos tempos escolares. Nessa proposta, os tempos e, por conseguinte, os espaços de formação se constroem entre os espaços da casa/comunidade e da escola. Ao se dividir os tempos e espaços formativos, esses se intercambiam contínua, dialógica e dialeticamente perdendo suas dicotomias e garantindo a unicidade necessária à construção de conhecimentos, universalizando-se o local.

Tal implica ainda uma constante "reconstrução" de conhecimentos e saberes que se reconfiguram em interações dialéticas e dialógicas, intercambiando-se de modo produtivo para a tomada de consciência da não neutralidade da ciência, bem como da necessidade da apropriação de conhecimentos, técnicas e instrumentos referendados e construídos pelo universal, mas ressignificados nos diferentes contextos locais de existência.

Nesse sentido, é produzido um conjunto de conhecimentos que, ao contrário de sociedades hegemônicas em que esta produção se localiza e se difunde de forma assimétrica, visto que institui e determina relações de poder, para a Educação do Campo o conhecimento se coloca a serviço da lógica da solidariedade e do bem-estar social.

Por fim, quer se destacar neste trabalho o posicionamento do II Conferência Nacional de Educação do Campo (CNEC), realizada em LuziâniaGO, em agosto de 2004, que se constitui 
em um exemplo importante de organização social na luta campesina. A declaração final do evento (Hage, Silva \& Brito, 2016) que propôs a construção de um processo de formação continuada, pública e gratuita com a participação de movimentos sociais e universidades públicas e que buscou valorização e formação específicas de educadores(as)do campo foi assinada por aproximadamente 1.100 representantes de movimentos sociais e das organizações sindicais de trabalhadores do campo e da educação, de universidades, de Organizações Não Governamentais (ONGs) e de Centros Familiares de Formação por Alternância, de secretarias estaduais e municipais de educação e de outros órgãos de gestão pública.

Assim, a Educação do Campo propõe a adoção de currículos que ajudem a ressignificar saberes, espaços, conhecimentos, crenças, suas vidas. Mas também evidencia de forma clara que não se faz educação sem que se considere a autonomia dos sujeitos nela envolvidos. As matrizes e práticas curriculares são determinadas em perspectiva conjunta, com a intencionalidade precípua de transformar os sujeitos que dela participam de modo pleno e livre. Nesse sentido:

A Educação do campo retoma a discussão e a prática de dimensões ou matrizes de formação humana que historicamente constituíram as bases, os pilares da pedagogia moderna mais radicalmente emancipatória, de base socialista e popular e de referencial teórico marxista, trazendo de volta o sentido de uma "modernidade da libertação" (Wallerstein, 2002, p. 133-50). Refiro-me como pilares ao vínculo entre educação e trabalho (não como "preparação para" da pedagogia liberal, mas como "formação desde" da pedagogia socialista), à centralidade dada à relação entre educação e produção ("nos mesmos processos que produzimos nos produzimos como ser humano"), ao vínculo entre educação e cultura, educação e valores éticos; entre conhecimento e emancipação intelectual, social, política (conscientização). Trata-se, afinal, de recolocar para discussão da pedagogia a concepção da práxis como princípio educativo, no sentido de constituidora fundamental do ser humano (Marx). E esta retomada vem exatamente da exigência do pensar a especificidade: considerar a realidade do campo na construção de políticas públicas e de pedagogia significa considerar os sujeitos da educação e considerar a prática social que forma estes sujeitos como seres humanos e como sujeitos coletivos. $\mathrm{E}$ não pretender que a educação/a pedagogia valha e se explique por e em si mesma. (Caldart, 2009, p. 42).

Por fim, como um último ponto a ser destacado, mas não menos importante, reafirma-se que a base para as proposições educacionais dos sujeitos do campo tem na posse e no uso da terra elementos constitutivos de suas propostas emancipatórias. Se essas populações foram vistas como "fracas" em termos de aprendizagem, pois, o pensamento de Aquino (2013, p. 34): 
É preciso ressaltar que os movimentos sociais do campo assumem como centralidade, dentre outras lutas, a luta pela terra. Há desafios a serem superados pela escola, pois historicamente as populações camponesas foram vistas como 'fracas em termos de aprendizagem'. Nesse sentido, é preciso que cada educador e educadora reflita sobre as origens, permanências e consequências de suas representações acerca dos povos do campo e de suas organizações sociais. Esta tarefa é importante, pois segundo Arroyo (2001, p. 177), 'sem mexer nos valores, crenças, autoimagens, na cultura profissional, não mudaremos a cultura política excludente e seletiva tão arraigada em nossa sociedade'.

\section{Considerações Finais}

Com vistas a alcançar uma educação que tenha no Protagonismo dos sujeitos do campo sua centralidade, os movimentos sociais têm organizado lutas no sentido de reconhecer esses sujeitos como cidadãos, logo como sujeitos de direitos. Assim, a luta por uma educação que possibilite a sua visibilidade, calcada no seu reconhecimento como sujeitos de direitos torna-se inerente à continuidade de sua existência/resistência.

Entende-se ainda que a educação é uma das possibilidades para a ascensão dos sujeitos não apenas do ponto de vista social, mas principalmente, apresenta-se como uma forma de combater a desigualdade impingida a esses sujeitos. Uma educação que se faça libertadora e que os "re-conheça" como protagonistas de suas histórias, calcada em princípios e diretrizes construídos por esses grupamentos sociais.

Pensar a posse da terra, ou seja, a reforma agrária só terá sentido caso se pensem em formas de construção desses espaços por àqueles a quem essa terra deveria pertencer. Entretanto, a sociedade brasileira calcou-se, desde os seus momentos iniciais de "construção" como uma sociedade excludente e por isso pouco afeita às escutas a necessidades de populações menos favorecidas economicamente. Os movimentos sociais do campo têm buscado evidenciar, a partir de seus processos de "re-construção" de si, que é possível constituir outros modelos de sociedade, mesmo que até o século $\mathrm{XX}$, século XXI o Brasil se mostre renitente em tomar consciência de suas necessidades.

Certamente, a história deste país precisa ser revisitada, revista e reconstruída para que se possa entender como se organizaram seus "primeiros" grupos organizacionais (a partir da invasão portuguesa). Tal "re-interpretação" histórica pode propiciar releituras dessa construção social que hoje se coloca. Buscar o passado para entender o presente? Talvez sim, mas buscar o passado principalmente para reorganizar formas de pensar, agir e sentir de homens e mulheres 
contemporâneos em busca de entendimentos sobre si mesmos. Revisitar ainda as histórias dos movimentos sociais que, embora muito próximas a este tempo, demonstram uma dinamicidade vigorosa, conforme se evidenciou neste artigo.

\section{Referências}

Aquino, L. V. (2013). Representações sociais de educandas e educandos do curso de licenciatura em Educação do Campo sobre a leitura de textos acadêmicos (Tese de Doutorado). Universidade Federal de Minas Gerais, Belo Horizonte.

Baleeiro, A. (1997). Limitações constitucionais ao poder de tributar. Rio de Janeiro: Forense.

Brasil. (1824). Constituição Federal de 1824. Recuperado de: http://www.planalto.gov.br/ccivil_03/Cons tituicao/Constituicao24.htm

Brasil. (1891). Constituição Federal de 1891. Recuperado de: http://www.planalto.gov.br/ccivil_03/Cons $\underline{\text { tituicao/Constituicao91.htm }}$

Brasil. (1934). Constituição Federal de 1934. Recuperado de: http://www.planalto.gov.br/ccivil_03/Cons tituicao/Constituicao34.htm

Brasil. (1946). Constituição Federal de $1946 . \quad$ Recuperado de: http://www.planalto.gov.br/ccivil_03/Cons tituicao/Constituicao46.htm

Brasil. (1964). Constituição Federal de 1964. Recuperado de: http://www.planalto.gov.br/ccivil_03/AIT/ ait-01-64.htm
Brasil. (1967). Constituição Federal de $1967 . \quad$ Recuperado de: http://www.planalto.gov.br/CCIVIL_03/Co nstituicao/Constituicao67.htm

Brasil. (1969). Ato Institucional de 1969. Recuperado de: http://www4.planalto.gov.br/legislacao/por tal-legis/legislacao-historica/atosinstitucionais

Brasil. (1988). Constituição Federal de 1988. Recuperado de: http://www.planalto.gov.br/ccivil_03/const ituicao/constituicao.htm

Caldart, R. S. (2009). Educação do campo: notas para uma análise de percurso. Trabalho, Educação e Saúde, 7(1), 35-64.

Ferreira, S. N. (2007). Direito de propriedade: nas Constituições brasileiras e do Mercosul. Revista Jurídica da Presidência, 8(83), 180-192.

Filho, J. L. A., \& Fontes, R. M. O. (2009). A formação da propriedade e a concentração de terras no Brasil. Revista de História Econômica \& Economia Regional Aplicada, 4(7).

Freire, P. (1987). Pedagogia do oprimido. Rio de Janeiro: Paz e terra.

Hage, S. A. M, Silva, H. S. A., \& Brito, M. M. B. (2016). Educação superior do campo: desafios para a consolidação da licenciatura em educação do campo. Educação em Revista, 32(4), 147-174. https://dx.doi.org/10.1590/0102$\underline{4698162036}$

Humanos, D. U. D. D. (2013). Adotada e proclamada pela resolução 217 A (III) da Assembléia Geral das Nações Unidas em 10 de dezembro de 1948. Recuperado de: www.direitoshumanos.usp.br 
Loureiro, Francisco Eduardo. (2003). A propriedade como relação jurídica complexa. Rio de Janeiro: Renovar, 2003.

Martins, F. J. (2013). Elementos Fundamentais da educação do campo. Educere et Educare, 8(15), 179-198. Recuperado de: http://erevista.unioeste.br/index.php/educereetedu care/article/viewFile/9200/6803

Molina, M. C., \& Freitas, H. C. A. (2011). Avanços e desafios na construção da educação do campo. Em Aberto, 24(85), 17-31.

Motta, M. C. M. (1997). Conceito constitucional de propriedade: tradição ou mudança? Rio de Janeiro: Lúmen Júris.

Oliveira, A. U., \& Stédile, J. P. (2005). Fórum Nacional de Reforma: A Natureza do Agronegócio no Brasil. Brasília: Secretaria Operativa.

Raffestin, C. (1993). Por uma geografia do poder. Tradução de Maria Cecília França. São Paulo: Ática.

Stélide, J. P. (Org.). (2002) História $e$ natureza das Ligas Camponesas. São Paulo: Expressão Popular.

Stélide, J. P. (1997). A questão agrária no Brasil. São Paulo: Atual.

Zen, E. T., \& Foerste, E. (2006). Discussões sobre Princípios para pensar Educação do Campo. Recuperado de: http://www.educacaodocampo.ufes.br/

\footnotetext{
i O escravo (negro) era considerado como "coisa", um "semovente", destituído de "alma", o que justificava a sua escravidão.
}

\footnotetext{
ii Essa exposição é feita com base em estudos de Motta: (1997), Baleeiro (1997), Loureiro (2003) e Ferreira (2007).

iii Disponível em: http://portal.inep.gov.br/censoescolar
}

Informações do artigo / Article Information

Recebido em : 14/01/2019

Aprovado em: 22/03/2019

Publicado em: 28/05/2019

Received on January 14th, 2019

Accepted on March 22th, 2019

Published on May, 28th, 2019

Contribuições no artigo: Os autores foram os responsáveis por todas as etapas e resultados da pesquisa, a saber: elaboração, análise e interpretação dos dados; escrita e revisão do conteúdo do manuscrito e; aprovação da versão final a ser publicada.

Author Contributions: The authors were responsible for the designing, delineating, analyzing and interpreting the data, production of the manuscript, critical revision of the content and approval of the final version to be published.

Conflitos de interesse: Os autores declararam não haver nenhum conflito de interesse referente a este artigo.

Conflict of Interest: None reported.

Orcid

Elizabeth Moreira Gomes

iD http://orcid.org/0000-0003-3711-1663

Alexandre Fraga de Araújo

iD http://orcid.org/0000-0003-0726-9208

Maria Isabel Antunes-Rocha

http://orcid.org/0000-0002-4044-6723

Como citar este artigo / How to cite this article

APA

Gomes, E. M., Araújo, A. F., \& Antunes-Rocha, M. I. (2019). Legislação sobre posse de terras e Educação do Campo no Brasil. Rev. Bras. Educ. Camp., 4, e6406. DOI: http://dx.doi.org/10.20873/uft.rbec.e6406

ABNT

GOMES, E. M.; ARAÚJO, A. F.; ANTUNES-ROCHA, M. I. Legislação sobre posse de terras e Educação do Campo no Brasil. Rev. Bras. Educ. Camp., Tocantinópolis, v. 4, e6406, 2019.2 DOI: http://dx.doi.org/10.20873/uft.rbec.e6406 